\title{
Functional Anatomical, Histological and Ultrastructural Studies of three Chameleon Species: Chamaeleo Chamaeleon, Chamaeleo Africanus, and Chamaeleon Vulgaris
}

\author{
Estudios Anatómicos, Histológicos y Ultraestructurales Funcionales de Tres Especies de Camaleón: \\ Chamaeleo Chamaeleon, Chamaeleo Africanus, y Chamaeleon Vulgaris
}

Yosra A. Fouda*; Dalia A Sabry* \& Dalia F. Abou-Zaid**

FOUDA, Y. A.; SABRY, D. A. \& ABOU-ZAID, D. F. Functional anatomical, histological and ultrastructural studies of three Chameleon Species: chamaeleo chamaeleon, Chamaeleo africanus, and chamaeleon vulgaris. Int. J. Morphol., 33(3):1045-1053, 2015.

SUMMARY: Three chamaeleon species including Chameleon Chamaeleo chamaeleon, Chameleon Chamaeleo africanus, and Chamaeleon vulgaris were collected and their tongue were dissected and examined morphologically and investigated using light and scanning electron microscopy. Both species showed similar histological manifestation of lingual papillae and tubular glands with dense mucous secretion especially in Chamaeleon vulgaris. There is no keratinization of lingual surfaces. Ultrastructurally, filliform represent the only pattern of lingual pappillae and take either cylindrical, conical and leaflet structure.Although the examined chalmaeleon species collected from different habitat, it shows almost similarities in their histological and ultrastructural structures.

KEY WORDS: Anatomical study; Histological study; Ultrastructural study; Tongue; lingual papillae; Chameleon Chamaeleo Chamaéleon; Chameleon Chamaeleo africanus; Chamaeleon vulgaris.

\section{INTRODUCTION}

The vertebrate tongue is an organ that is crucial to a wide variety of functions, including important roles in prey transporting and swallowing, drinking, breathing, and even chemoreception, as well as, prey capture in some groups, such as lizards (Schwenk 2000; Herrel et al., 2001a). Thus, specialization of the tongue may be constrained by functional trade-offs imposed by the different functions. The form of the tongue has long been considered as an important character in squamate classification (Schwenk, 1988). In iguanid and agamid lizards, which typically do rely on interlocking for prey prehension, the area of the tongue (Schwenk, 1985) that contacts the prey is characterized by large numbers of plumose papillae (Herrel et al., 1998; Delheusy et al., 1994; Schwenk, 2000). Chameleons diverge from the primitive prey capture mode by projecting their tongue ballistically up to twice their body length to capture prey (Wainwright et al., 1991). Although the chameleon tongue is generally considered to be an example of an adhesive bonding system (Bramble \& Wake, 1985), suction was suggested as a possible mechanism that would enable chameleons to capture large, smooth prey (Schwenk, 1983). Chameleons have undoubtedly received more attention from anatomists and functional morphologists than any other reptile. In particular, the ballistic tongue projection mechanism of chameleons has stimulated an unusually large body of work (Herrel et al., 2001b).

Tongue prehension was the predominant prey capture mode in all members of the most primitive lizard clade, the Iguania (i.e. Iguanidae, Agamidae, and Chamaleonidae). The mechanism by which the prey adheres to the tongue of iguanid lizards during capture was thought to be based on adhesive bonding and/or interlocking (Bramble and Wake, 1985). Since the chameleon tongue pad contains a large number of epithelial glands and possesses numerous papillae that can lock into surface irregularities on the prey (Schwenk, 1983), Both wet adhesion and interlocking presumably played an important role during prey capture. Although the chameleon tongue is generally considered to be an example of an adhesive bonding system (Bramble \& Wake), suction was suggested as a possible mechanism that would enable chameleons to capture large, smooth prey (Schwenk, 1983). Indeed, because the strength of the adhesive bond was limited by the surface area of the tongue contacting the prey (Emerson \& Diehl, 1980), this system places severe limitations on the maximal prey size that

* Zoology Department, Faculty of Science, Mansoura University, Mansoura, Egypt.

** Zoology Department, Faculty of Science, Tanta University, Tanta, Egypt. 
can effectively be transported by the tongue. The most interesting histological feature of reptilian tongues reflect adaptations to a dry habitat but stratification and keratinization of the lingual epithelium were the most common features (Iwasaki, 1990; Iwasaki \& Kumakura, 1994; Toubeau et al., 1994). By contrast, the American chameleon's tongue is intimately involved in feeding. A large part of the lingual epithelium consists of cells with secretory granules, many of which are mucous granules and some are serous granules (Rabinowitz \& Tandler, 1986). Thus the shape and structure of the tongue differ significantly among reptiles, reflecting the various functions of each respective tongue. The agamid tongue projection mechanism appears to be an ideal mechanical precursor for the ballistic tongue projection mechanism of chameleonids; the key derived feature in the chameleon tongue projection mechanism most likely lies in the changed motor pattern controlling the hyoglossus muscle (Herrel et al., 1995).

Concerning this study, there is a little information of the lingual histology and ultrastructure of Chameleon Chamaeleo chamaeleon (Linnaeus, 1758), Chameleon Chamaeleo africanus Laurenti, 1768, and Chamaeleon vulgaris Daudin, 1802. They inhabit North Africa, Turkey, and the near and Middle East (Martin, 1992; Hodar et al., 2000). Although the studied species belong to the chameleonidae species, they show diversity of their anatomical, histological and ultrastructural components. The present study analyses the differences of the structural components in relation with their environmental habitat and feeding habits.

\section{MATERIAL AND METHOD}

Fifteen adult species of Chameleon Chamaeleo chamaeleon (Linnaeus, 1758) (order Squamata, suborder, Sauria, Family Chamaeleonidae, subfamily Subfamilia: Chamaeleo), Chameleon Chamaeleo africanus (Laurenti, 1768) (order Lacertilia, suborder, Sauria, Family Chamaeleonidae), and Chamaeleon vulgaris (Daudin, 1802) are used in the present work.

The first and second species are collected from Giza Governorate, Abou-Rawash zone; meanwhile the third one is gathered from Sidi-barani, south of the Egypt. Classification is carried out according to Klaver \& Böhme (1986). They are sacrificed, dissected and tongue was removed and processed for investigations the following parameters:

Morphological studies: For morphological studies, the tongue specimens are removed, photographed, and described.
Histological studies: Fresh tongue specimens are immediately fixed in $10 \%$ formol saline, dehydrated in ascending grades of ethyl alcohol, cleared in zylol and mounted in molten paraplast $58-62{ }^{\circ} \mathrm{C}$. Five $\mu \mathrm{m}$ thick histological sections are cut and stained with haematoxylin and eosin and Mallory triple stain. Samples are investigated by bright field light microscopy.

Scanning electron microscopic study: For topographic studies, extra tongue specimens are fixed in $10 \%$ formal saline for $24 \mathrm{~h}$, followed by dehydration in ascending ethanol series. The specimens were carefully mounted on aluminum stages with double-sided carbon tape, and critical point dried. The samples are mounted on metal stubs, coated with gold, and observed at various different angles with Jeol scanning electron microscope at accelerating voltages of 5 or $10 \mathrm{kV}$.

\section{RESULTS}

Gross morphology. Macroscopically, the tongue is composed of three differentiated successive zones. The

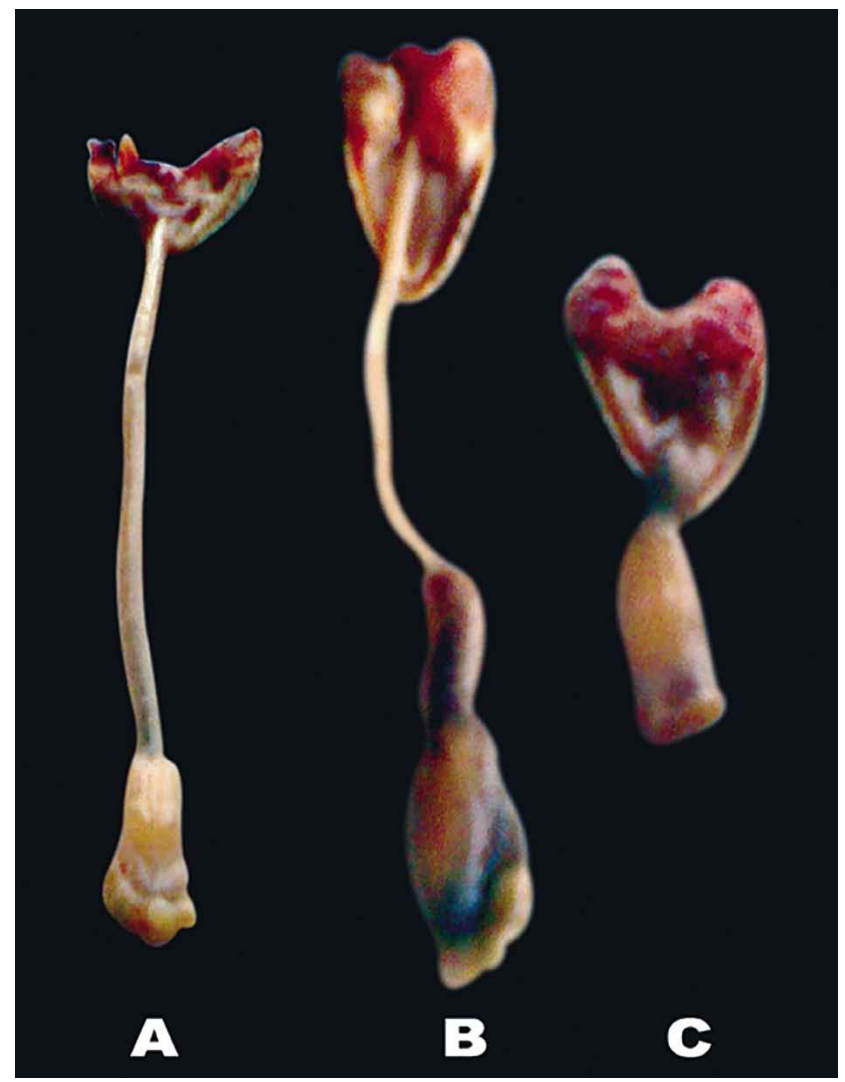

Fig. 1. Gross morphology of lingual region of C. chameleon (A), C. africana (B) and C. vulgaris. 
proximal, middle, and root part. The proximal part is a textured mass markedly flattened, thickened, and sticky with saliva. It takes different shape structures that varied between the studied chameleon species.

In C. chameleon, it appeared flattened pear-shaped structure with broad free end. At the free end, the dorsal surface displayed three dome- shaped structures. However, in C. africana, it shows flattened, large size, and tie - shaped structure with collar end that attached to the median region. In $C$. vulgaris, the proximal part is flattened and conical-shaped in structure and showed comparatively moderate size. The median sulcus is ill-differentiated on the dorsal surface of the tongue.

The middle part of the tongue, which protrudes out of the mouth during the tongue flicking, is elongated tube-like structure and appeared fleshy formed of muscular tissue. It is long in length in $C$. chameleon, where in C. africana it is somewhat short, however, in C. vulgaris the middle part is represented by a fine connection point.

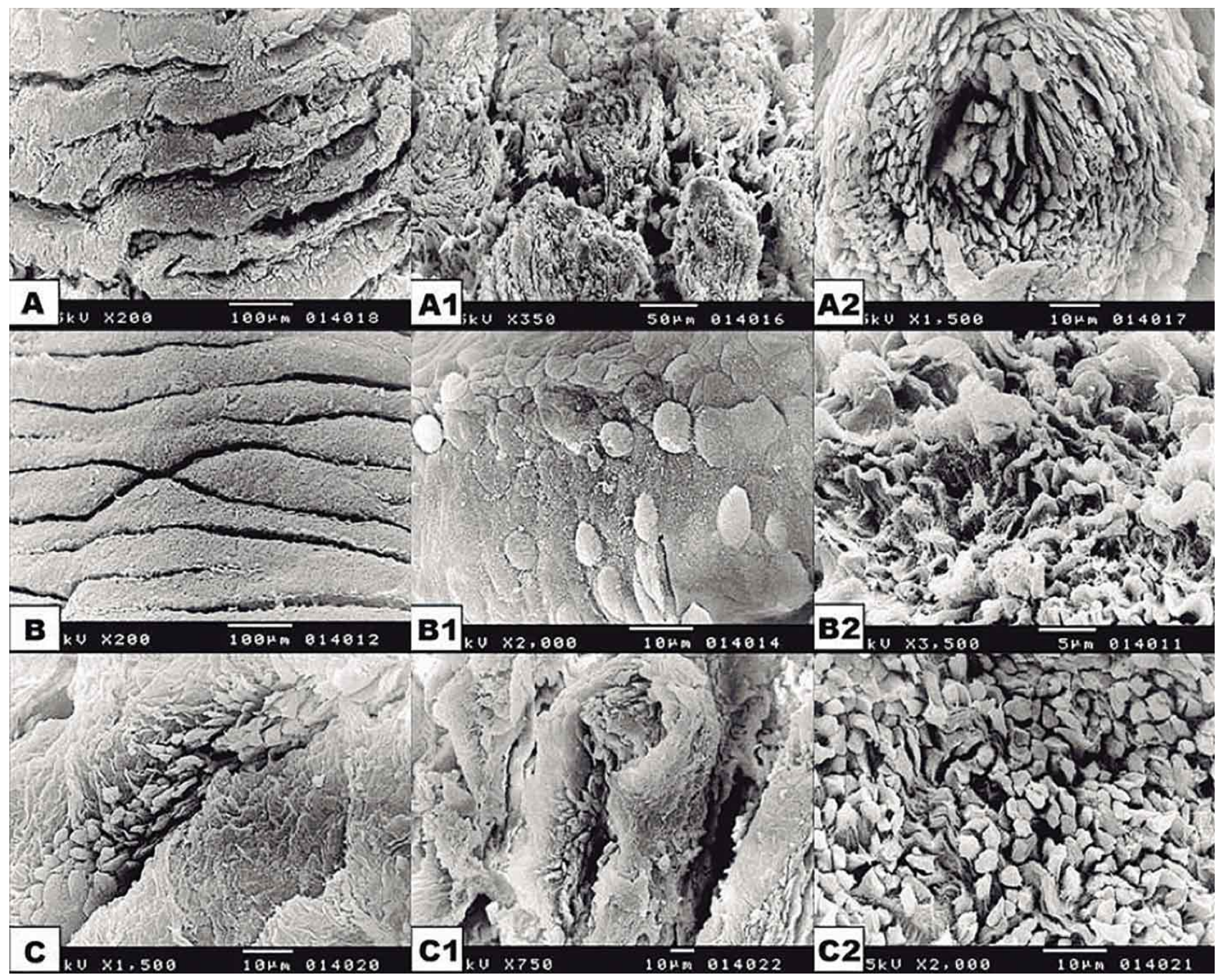

Fig. 2. Scanning electron micrographs of the proximal region of the dorsal surface of Chameleons tongue. In C. chameleon species, showing transverse rows of dense cylindriform papillae separated by grooves at the apex of the proximal region of the tongue (A); at higher magnification of the same area, note the conical papillae (A1); and note the collectively rosette-form structure of grouping papillae in the middle part of the proximal region of the tongue (A2). In C. africana showing longitudinal flattened strands at the apex of proximal part of the mucosal surface (B); at higher magnification, of the same area showing, a fungiform papillae; taste buds; flattened epithelial cells and numerous mucus secretions (B1) and at the posterior region of the proximal part of the tongue showing a different pattern of lingual papillae as leaves - like papillae; it is separated by a deep folds (B2). In C. vulgaris showing a longitudinal column papillae at the apex of the proximal part of the mucosal surface (C); also showing a slender papillae, some parts are covered by flattened epithelial cells. The limits between the cells are clear (C1); and showing a crowded tall slenderical papillae (C2) at the middle part of the proximal region. 
FOUDA, Y. A.; SABRY, D. A. \& ABOU-ZAID, D. F. Functional anatomical, histological and ultrastructural studies of three Chameleon Species: Chamaeleo chamaeleon, Chamaeleo africanus, and

The posterior part of the tongue, which remained almost entirely within the mouth during protrusion, is inverted arrow-shaped structure in C. cameleon, in C. africana it is triangular in shape, where, in C. vulgaris it is heart in shape (Fig. 1. A-C).

Scanning electron microscopy. The present study deal the structure of the tongue, revealed that the proximal region of the tongue can be distinguished into three parts; apex, middle, and posterior part. The lingual mucosa of the apex of proximal region of the tongue of the studied species is composed of transverse rows of dense cylindriform papillae separated by a median grooves connected internally by muscular structures (Fig. 2 A-C). Each row of lingual strand surfaces carried three different forms of papillae; the first form has conical form in the apex of proximal region of $C$. chameleon (Fig. 2-A1) and the second form is leaves structure papillae, which are separated by a deep fold as shown in the posterior part of the proximal region of the mucosal surface of the C. africana (Fig. 2-B2). The third type acquires slender filamentous-pattern as in the middle part of the proximal region of the tongue of $C$. vulgaris (Fig. 2-C2).

At higher magnification of the middle region of the proximal part of the tongue of $C$. chameleon located a collectively rosette - form structure of grouping papillae (Fig. 2-A2). At the dorsal surface of the apex of the proximal region of the tongue of C. africana, fungiform papillae, few taste buds, flattened epithelial cells, and heavy mucus secretions are detected through out the lingual surface (Fig. 2-B1). Enlarged part of the apex of proximal portion of the

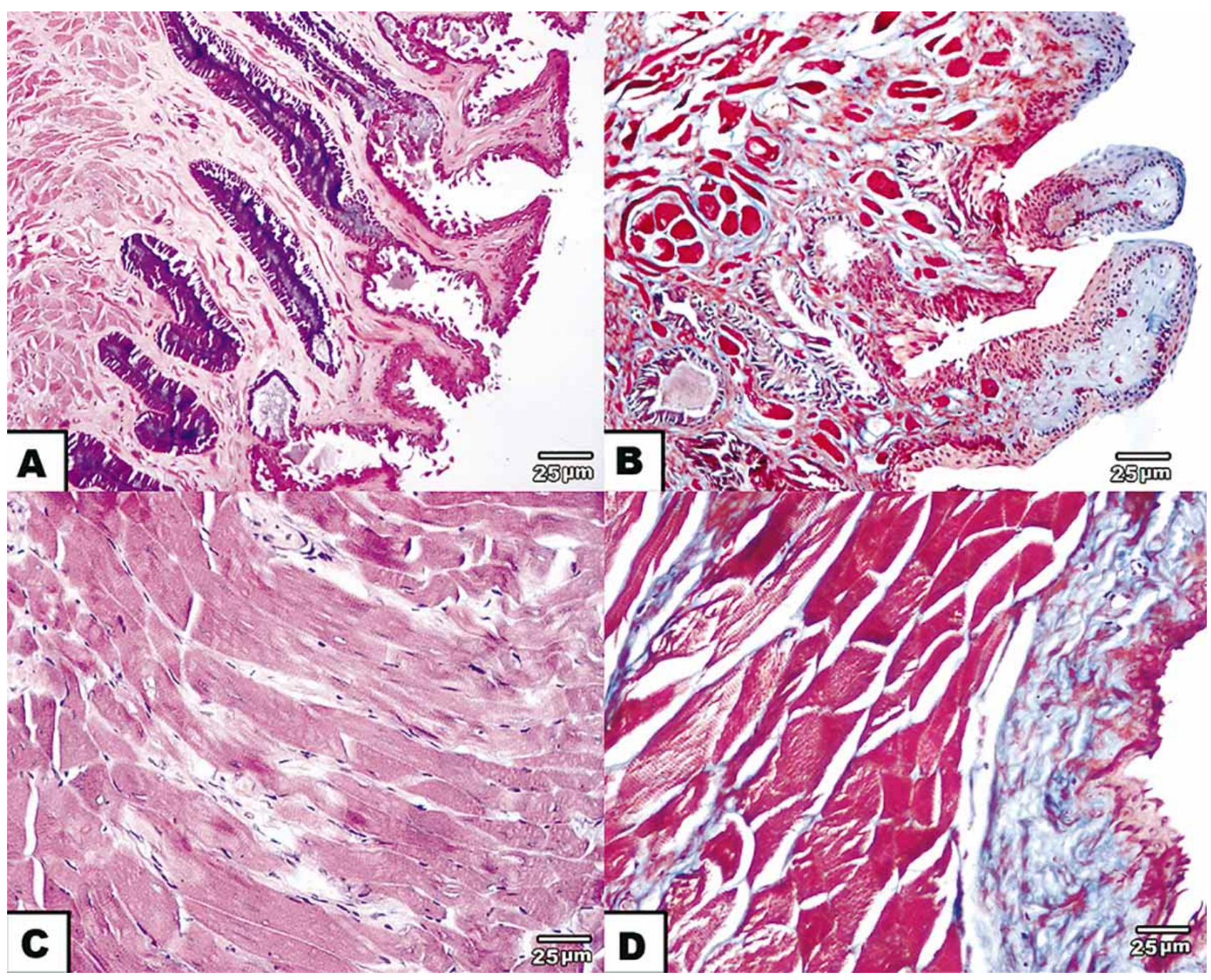

Fig. 3. Photomicrographs of T. S. of the lingual mucosa of the tongue of C. chameleon. A) Conical filiform papillae formed of columnar epithelium containing tubular gland. B) Median part of the proximal part of the tongue containing filiform papillae. C) Circular striated muscle fibers. D) Posterior part of the dorsal surface of the tongue, rich with smooth connective tissue (A and C, H\&E stain; B and D, Mallory triple). 
dorsal surface of the tongue of $C$. vulgaris showed a slender papillae, also some parts are covered by flattened epithelial cells, the limits between the cells are clear as shown in Figure 2-C1.

Histological observation. At the light microscopic level, the lingual mucosa of the studied species is covered with different patterns of lingual papillae, which are widely distributed all over the dorsal surface. The lingual papillae are regularly arranged with their curved pointed edge directed posteriorly to the tongue root. The lingual mucosa formed the superficial layer, underneath it, a loose connective tissue infiltrated in-between the blood vessels.

The lingual mucosa is composed of a conical filiform lingual papillae lined by columnar epithelium and maintained internally forming tubular glands enclosed in between mucous cells, this is mainly detected in C. chameleon, and the keratinization is not detected (Figs. $3 \mathrm{~A}$ and $\mathrm{B}$ ). Meanwhile, the lingual papillae become formed of stratified columnar epithelium in C. africana and C. vulgaris. Also the keratinization is poor in (Figs. 4 and 5A-B). Numerous goblet cells are distributed in-between the lining cell, the mucous secretion is densely observed in $C$. vulgaris compared with the other species.

The papillae have dense connective tissue core containing numerous blood vessels, and infiltrated by the lingual striated muscles, which arranged in circular pattern. In the middle part of the proximal region of the tongue, the densely grouping of circular muscle surrounded by a connective tissue is suspected for contraction and retraction of the tongue (Fig. 5 B-D). This pattern structure is highly detected in C. chameleon and C. africana (Figs. 3 and 4C-D).

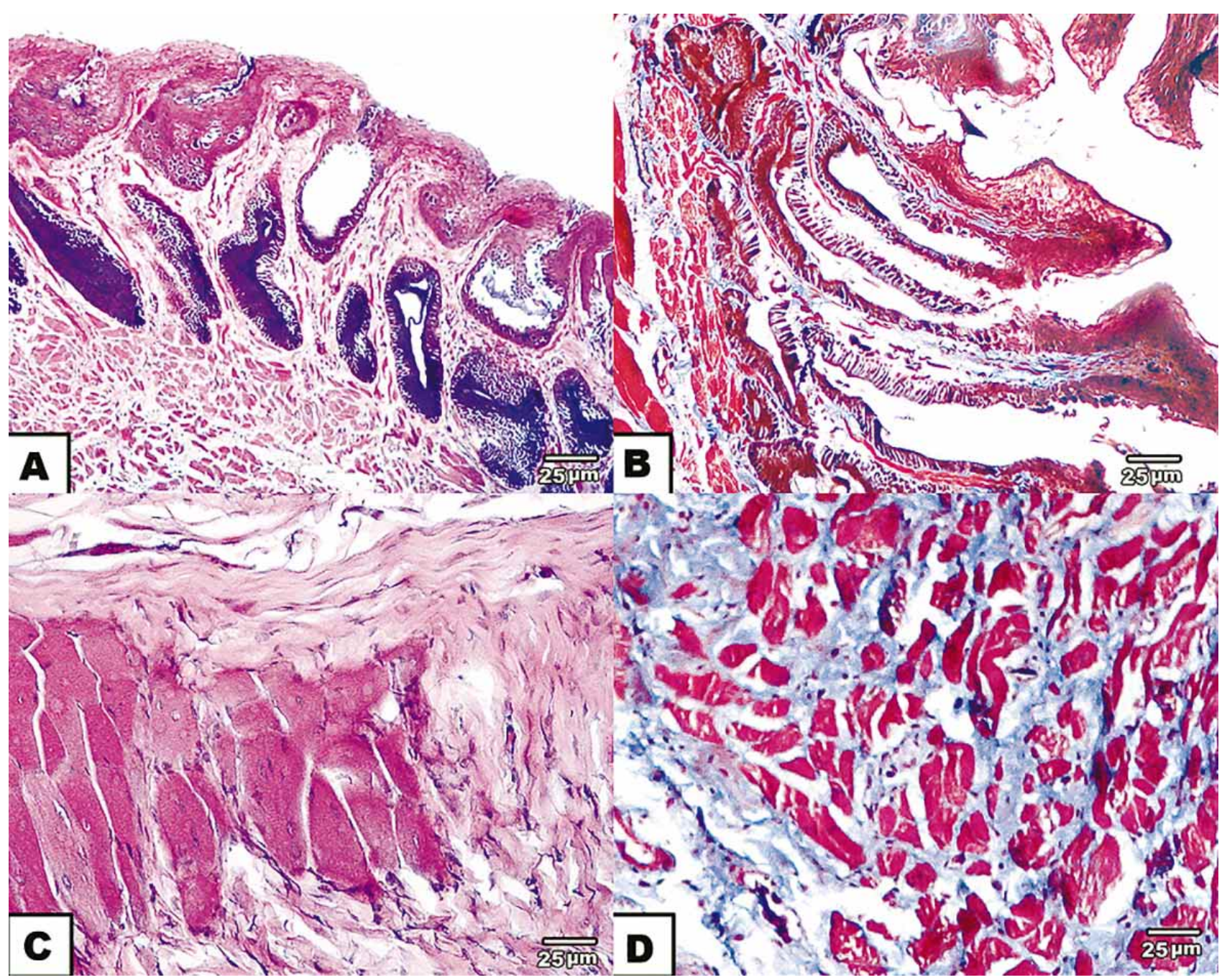

Fig. 4. Photomicrographs of transverse histological sections of the lingual mucosa of the tongue of C. africanus. A) The papillae covered by stratified columnar epithelium containing tubular gland. B) Tip of tongue containing cylindrical filiform papillae. C and D striated muscle fibres infiltrated by connective tissue (A and C, H\&E stain; B and D, Mallory triple). 


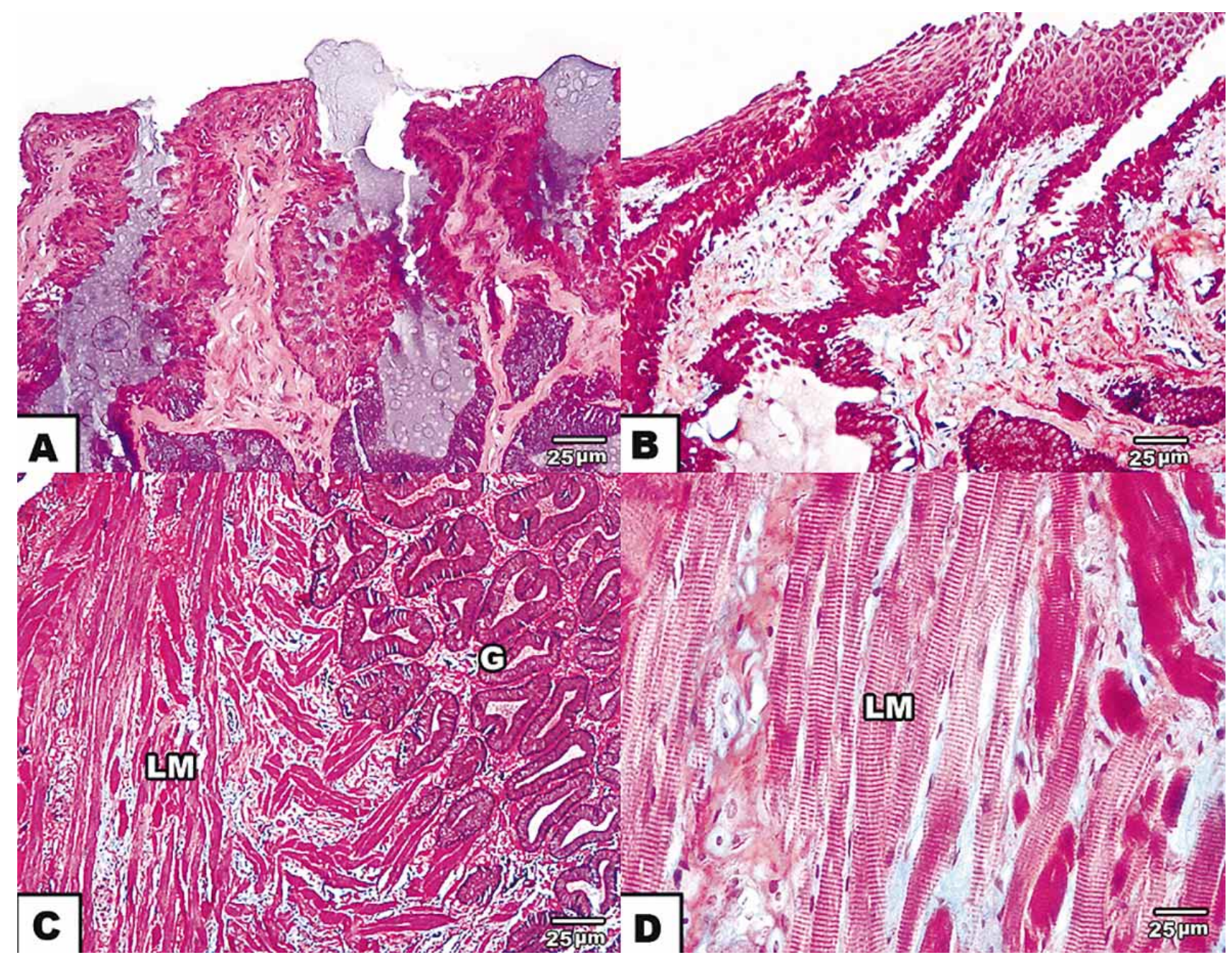

Fig. 5. Photomicrographs of T.S. of the tongue of C. vulgaris. A and B). Showing the cylindrical filiform papillae, covered by stratified columnar epithelium. C). Showing tubular gland in the mucosal layer. D). Showing striated circular muscle fibers infiltrated by connective tissue (A and C, H\&E stain; B and D, Mallory triple).

\section{DISCUSSION}

The present study dealt with the structure of the tongues of three chameleon species; C. chameleon, $C$. africana, and C. vulgaris. the tongue is composed of three differentiated successive zones. The proximal, middle, and root part. The results showed morphological variations between the three species. In C. chameleon, the proximal part is small in size, appears flattened, pear-shaped structure, and at the free end of the dorsal surface displayed three dome- shaped structures. in C. africana, it shows flattened, large in size, and tie-shaped structure, however, In C. vulgaris, it is flattened and conical-shaped structure. The median sulcus is absent in the three species, and the apex is generally blunt. This agrees with Herrel et al. (2001) who described that the bifurcation was almost absent in chameleons. However, de Groot et al. (2004) in Python molurus, El- Sayyad et al. (2011) in Psammophis sibilans, and Darwish (2012) in ptyodactylus guttatus and Stenodactylus petrii (Lacertilia, Gekkonidae), reported that the apex is bifurcated.

Scanning electron microscopic observations revealed the presence of transverse rows of dense cylindriform papillae separated by a median grooves connected internally by muscular structures. Three different forms of papillae; conical, leaflet like structure and slender filamentous-forms. Slender pappillae are detected in the 
median part of the proximal tongue region of $C$. vulgaris. Towards the posterior side of the fore-tongue, the papillary arrangement in transverse rows disappears laterally. The hind-tongue of chameleons is mostly devoid of papillary structures and consists of a smooth epithelial structure. Upon return of the tongue to the mouth, the tongue pad with prey moves back faster than it can be reeled in by the tongue retractor, resulting in it being frequently catapulted back beyond the head of the animal (Bell, 1990).

Poor Keratinization of the dorsal lingual epithelium of C. africana and C. vulgaris are detected. Reduction of the keratinization is confirmed by decreasing of keratohyaline granules in the keratinocytes of the stratum granulosum layer. These cells are the source of the stratum corneum. Keratinization of the dorsal lingual epithelium has been recognized in higher vertebrates. Among reptiles, Iwasaki et al. (1996) revealed that the keratinization of the lingual epithelium occurred, in evolutionary term, in conjunction with adaptation to dry land from a fresh water environment. In lizards, the keratinization is represented at the tip of tongue only (Wassif, 2001). Similar findings were described by Iwasaki \& Miyata (1985) in Japanese lizard, Takydromus tacydromoides and Iwasaki in Gekko japonicus.

Light and scanning electron microscopic observations of the tongue of the studied species revealed the presence of three types of dorsal lingual filiform papillae with different forms including conical-shaped, leaves-shaped or slender longitudinal form. The distribution of these papillae supports their mechanical function for transporting and swallowing of food materials.

The papillary structure of lizard tongues has been invoked in various functional attributes such as prey capture and transport (Herrel et al., 1998). Whereas plumose papillae are assumed to play an important role in the interlocking of the tongue onto prey surface irregularities (Schwenk, 2000), densely packed reticular papillae with prominent microstructure are assumed to play an important role during prey transport (Herrel et al., 1998). Surprisingly, in the chameleon species examined here, very little spatial variation in papillary structure was observed. Moreover, very few plumose papillae were observed in the so-called pouch or dimple, as would have been expected given that this is the area of the tongue contacting the prey during capture.

Also, the feeding habits varied between the examined species being fed in soft insects like butterfly in case of $C$. chameleon and $C$. africana as a result of living around the River Nile in the north of Egypt and the third fed on hard cutaneous insects and live in west of Egypt. The lingual papillae are regularly arranged on the dorsal surface of the tongue. Goblet cells are present in the lining epithelial cells of the inter-papillary ridge of the papillae, it secretes mucoid secretion that play a great role during capturing of the food materials. Dense mucoid secretion and stratification of lingual epithelium are highly detected in $C$. vulgaris. The dorsal lingual surface is decorated by striated strands separated by deep furrows, which hold internally by muscle strand. These ordinary structure made more flexibility and facilitated great movement of tongue for prey. In addition, the anterior tongue region exhibits irregular distribution of serrated cylindrical filaments either solitary or in groups that emerged in between the lingual strands. These serrated filaments possess important function for prey capture.

According to Bramble \& Wake, the prehensile tongue was the predominant prey capture mode in all members of the most primitive lizard clade, the Iguania (i.e. Iguanidae, Agamidae and Chamaeleonidae). The mechanism by which the prey adheres to the tongue of iguanid lizards during capture was thought to be based on adhesive bonding and/or interlocking. Since the chameleon tongue pad contained a large number of epithelial glands and possesses numerous papillae that can lock into surface irregularities on the prey, both wet adhesion and interlocking presumably played an important role during prey capture (Schwenk, 1983).

It is generally thought that chamaeleons, like other iguanians, rely on serous and mucous secretions and on interlocking to hold the prey on the tongue after capture (Bramble \& Wake; Bell). Based on morphological and photographic data, Schwenk (1983) suggested that during prey capture, the tongue hits the prey and is splayed, resulting in the forcible discharge of mucous. Interlocking by freestanding cells on the tongue surface and suction were also put forward as possible adhesive mechanisms. The same author revealed that suction played an important role in the mechanics of chameleon tongue prehension. More than two-thirds of the total force generated by the tongue in chameleons was due to suction, thus enabling the animals to capture much larger prey (up to $15 \%$ of their body mass) than would be possible using surface phenomena alone. The maximum size of prey effectively transported with the tongue in a generalized agamid lizard, Plocederma stellio, was approximately $5 \%$ of its body mass; but, regarding the strength of adhesive bonding in Phrynocephalus helioscopus (Schwenk, 2000). Carnivorous feeding of the animals reflected on the presence of slight cornification of the lingual surface at light microscopic level. 
The structural component of the central nervous system of the C. vulgaris reflected the capacity of prohension. The great excursion of the tongue is associated with a highly differentiated hypoglossal nucleu (Shanklin, 1930).

FOUDA, Y. A.; SABRY, D. A. \& ABOU-ZAID, D. F. Estudios anatómicos histológicos y ultraestructurales funcionales de tres especies de camaleón: chamaeleo chamaeleon, Chamaeleo africanus, y chamaeleon vulgaris. Int. J. Morphol., 33(3):1038-1044, 2015.

RESUMEN: Fueron recolectadas tres especies de Camaleón incluyendo Camaleón Chamaeleo chamaeleon, Camaleón Chamaeleo africanus y Chamaeleon vulgaris. Se disecó su lengua y examinó morfológicamente mediante el uso de microscopía de luz y electrónica de barrido. Ambas especies mostraron características histológicas similares en relación a las papilas linguales y glándulas tubulares con secreción mucosa densa, especialmente el Chamaeleon vulgaris. No hubo queratinización de las superficies linguales. Ultraestructuralmente, el único patrón de papilas linguales fue el filiforme, tomando una estructura ya sea cilíndrica, cónica y de hoja. Aunque las especies de Camaleón examinadas se recogieron de diferentes hábitat, ellas mostraron similitudes en su estructura histológica y ultraestructural.

PALABRAS CLAVE: Estudio anatómico; Estudio histológico; Estudio ultraestructural; Lengua; Papilas linguales; Chameleon Chamaeleo Chamaéleon; Chameleon Chamaeleo africanus; Chamaeleon vulgaris.

\section{REFERENCES}

Bell, D. A. Kinematics of prey capture in the chameleon. Zool. Jb. Physiol., 94:247-60, 1990.

Bramble, D. M. \& Wake, D. B. Feeding mechanisms of lower tetrapods. In: Hildebrand, M.; Bramble D. M. \& Wake, D. B. (Eds.). Functional vertebrate morphology. Cambridge, Harvard University Press, 1985. pp.230-61.

Darwish, S. T. Comparative histological and ultrastructural study of the tongue in Ptyodactylus guttatus and Stenodactylus petrii (Lacertilia, Gekkonidae). J. Am. Sci., 8(2):603-12, 2012.

de Groot, J. H.; van der Sluijs, I.; Snelderwaard, P. C. \& van Leeuwen, J. L. A three-dimensional kinematic analysis of tongue flicking in Python molurus. J. Exp. Biol., 207(Pt. 5):827-39, 2004.

Delheusy, V.; Toubeau, G. \& Bels, V. L. Tongue structure and function in Oplurus cuvieri (Reptilia: Iguanidae). Anat. Rec., 238(2):263-76, 1994.
El-Sayyad, H. I. H.; Sabry, D. A.; Khalifa, S. A.; Abou-El-Naga, A. M. \&. Foda, Y. A. Studies on tongue of reptilian species Psammophis sibilans, Tarentola annularis and Crocodylus niloticus. Int. J. Morphol., 29(4):1139-47, 2011.

Emerson, S. B. \& Diehl, D. Toe pad morphology and mechanisms of sticking in frogs. Biol. J. Linn. Soc., 13(3):199-216, 1980.

Herrel, A.; Meyers, J. J.; Nishikawa, K. C. \& Vree, F. D. The evolution of feeding motor patterns in lizards: modulatory complexity and constraints. Am. Zool., 41(6):1311-20, 2001a.

Herrel, A.; Meyers, J. J.; Nishikawa, K. C. \& De Vree, F. Morphology and histochemistry of the hyolingual apparatus in chameleons. J. Morphol., 249(2):154-70, 2001 b.

Herrel, A.; Timmermans, J. P. \& De Vree, F. Tongue flicking in agamid lizards: morphology, kinematics, and muscle activity patterns. Anat. Rec., 252(1):102-16, 1998.

Herrel, A.; Cleuren, J. \& De Vree, F. Prey capture in the lizard Agama stellio. J. Morphol., 224(3):313-29, 1995.

Herrel, A.; Meyers, J. J.; Nishikawa, K. C. \& De Vree, F. Morphology and histochemistry of the hyolingual apparatus in chameleons. J. Morphol., 249(2):154-70, 2001.

Hodar, J. A.; Pleguezuelos, J. M. \& Poveda, J. C. Habitat selection of the common chameleon (Chamaeleo chamaeleon) (L.) in an area under development in southern Spain: implications for conservation. Biol. Conserv., 94(1):63-8, 2000.

Iwasaki, S. Fine structure of the dorsal lingual epithelium of the lizard, Gekko japonicus (Lacertilia, Gekkonidae). Am. J. Anat., 187(1):12- 20, 1990.

Iwasaki, S.; Asami, T. \& Wanichanon, C. Fine structure of the dorsal lingual epithelium of the juvenile hawksbill turtle, Eretmochelys imbricata bissa. Anat. Rec., 244(4):437-43, 1996.

Iwasaki, S. \& Kumakura, M. An ultrastructural study of the dorsal lingual epithelium of the rat snake, Elaphe quadrivirgata. Ann. Anat. 176:455-462, 1994.

Iwasaki, S. \& Miyata, K. Scanning electron microscopy of the lingual dorsal surface of the Japanese lizard, Takydromus tachydromoides. Okajimas Folia Anat. Jpn., 62(1):15-25, 1985.

Klaver, C. \& Böhme, W. Phylogeny and classification of the Chamaeleonidae (Sauria) with special reference to hemipenis morphology. Bonn. Zool. Monograph., 22:1-64, 1986.

Martin, J. Chameleons: Nature's Masters of Disguise. London, Blandford, 1992.

Rabinowitz, T. \& Tandler, B. Papillary morphology of the tongue of the American chameleon: Anolis carolinensis. Anat. Rec., 216(4):483-9, 1986. 
FOUDA, Y. A.; SABRY, D. A. \& ABOU-ZAID, D. F. Functional anatomical, histological and ultrastructural studies of three Chameleon Species: Chamaeleo chamaeleon, Chamaeleo africanus, and Chamaeleon vulgaris. Int. J. Morphol., 33(3):1045-1053, 2015.

Schwenk, K. Functional morphology and evolution of the chameleon tongue tip. Am. Zool., 23(4):1028, 1983.

Schwenk, K. Occurrence, distribution and functional significance of taste buds in lizards. Copeia, 1:91-101, 1985.

Schwenk, K. Feeding in lepidosaurs. In: Schwenk, K. (Ed.). Feeding: Form, function and evolution in tetrapod vertebrates. San Diego, Academic Press, 2000.

Schwenk, K. \& Bell, D. A. A cryptic intermediate in the evolution of chameleon tongue projection. Experientia, 44(8):697$700,1988$.

Shanklin, W. M. The central nervous system of Chameleon vulgaris. Acta Zool., 11(2-3):425-90, 1930.

Toubeau, G.; Cotman, C. \& Bels, V. Morphological and kinematic study of the tongue and buccal cavity in the lizard Anguis fragilis (Reptilia:Anguidae). Anat. Rec., 240(3):42333, 1994.

Wassif, E. T. The fine structure of the dorsal lingual epithelium of the scincine lizard Chalcides ocellatus Forscal (Scncidea, Sauria, Reptilia). I. Histogenesis of the lingual epithelium. Egypt. J. Biol., 3:12-9, 2001.

Wainwright, P. C.; Kraklau, D. M. \& Bennett, A. F. Kinematics of tongue projection in Chamaeleo oustaleti. J. Exp. Biol., 159:109-33, 1991.

\section{Correspondence to: \\ Yosra A. Foda \\ Zoology Department \\ Faculty of Science \\ Mansoura University \\ Mansoura \\ EGYPT}

Email: elsayyadem51@gmail.com

Received: 17-01-2015

Accepted: 20-05-2015 